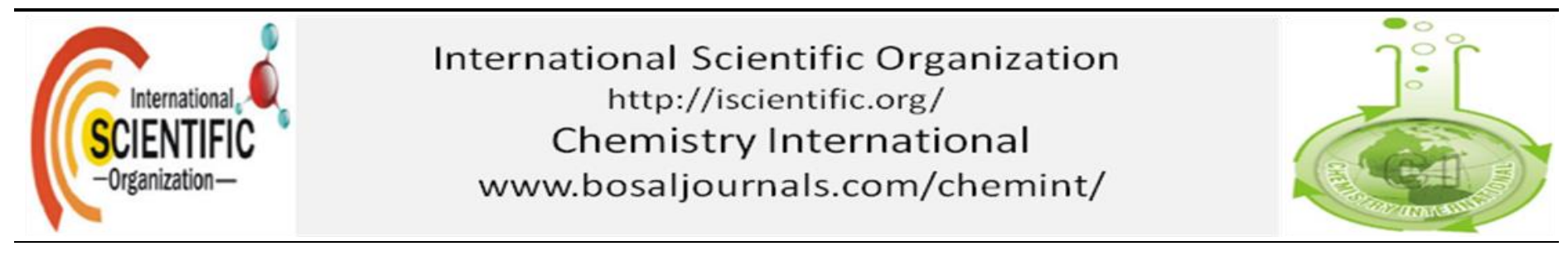

\title{
Reactors functional parameters for sodium benzoate production: A comparative study
}

\section{Chukwuemeka Peter Ukpaka}

\author{
Department of Chemical/Petrochemical Engineering, Rivers State University, Port Harcourt, Nigeria \\ *Corresponding author's E. mail: chukwuemeka24@yahoo.com, peter.ukpaka@ust.edu.ng
}

\section{A R T I C L E I N F O}

\section{Article type:}

Research article

Article history:

Received March 2018

Accepted October 2018

April 2019 Issue

Keywords:

Continuous Stirred-Tank Reactor

Batch reactor

Plug flow reactor

Sodium benzoate production

\section{A B S T R A C T}

The various process performances of the Batch Reactor, Continuous Stirred-Tank Reactor (CSTR) and Plug Flow Reactor (PFR) for the production of sodium benzoate from the reaction of sodium hydroxide and benzoic acid were investigated. The performance equations for the operation of Batch reactor, CSTR and PFR were developed for the analysis of the reactor's functional dimensions and parameters. The analysis of the reactor's functional parameters was performed at molar ratio of benzoic acid to sodium hydroxide of 1.5 to 3.0 at intervals of 0.5 and at the same reactor operating conditions. The set of reactors' performance equations were solved simultaneously and then, simulated with the aid of MATLAB R2015a computer program. However, in terms of comparison at the same operating conditions, the size of the batch reactor was greater than that of CSTR which in turn was greater than that of the PFR, while the reverse was the case for heat generated per reactor volume. Also, the space time for CSTR was greater than that of the PFR while the space velocity for PFR was greater than that of CSTR. Following the results obtained from the analysis, the production of sodium benzoate from sodium hydroxide and benzoic acid can be executed in either of batch reactor, CSTR or PFR depending on the capacity of production and conditions of operation and the optimum performance was observed at molar feed ratio of 3.0.

(c) 2019 International Scientific Organization: All rights reserved.

Capsule Summary: This work demonstrates the usefulness of batch reactor, CSTR and plug flow reactor in the production of sodium benzoate. The developed model was simulated using MATLAB R 2015a computer program to determine the functional parameters that control the system.

Cite This Article As: C. P. Ukpaka. Reactors functional parameters for sodium benzoate production: A comparative study. Chemistry International 5(2) (2019) 143-157. https://doi.org/10.5281/zenodo.1487997

\section{INTRODUCTION}

For efficiency of any process, especially reactors, the operating variables are of utmost important, because at a certain values they not only improve the system performance, but also return profit. So for reactors, temperature, pressure, flow rate, process catalyst and other factors, are important variables in determining the efficiency of reactors. The production of sodium benzoate from sodium hydroxide and benzoic acid occurs at atmospheric pressure and temperatures between ambient and slightly above the ambient temperature. Kralj (2012), while investigating the kinetic of sodium benzoate from sodium hydroxide and benzoic acid, varied the reactor temperature between 16.1 to $18.5^{\circ} \mathrm{C}$, at atmospheric pressure and varying molar feed 
ratios. For successful production of new substance involving chemical reaction, reacting vessel or otherwise known as reactor must be designed or made available. However, several types of reactors are used in chemical industries depending on the nature of the reacting species, economic cost, product yield, performance and other process conditions necessary to achieve high profit at best operating cost. According to Srour (1998), the major application of sodium benzoate is as a preservative in the soft drinks and beverages industries as a result of the demand for highfructose corn syrup on carbonated beverages. Interestingly, sodium benzoate is extensively used in acidic foods such as salad dressings (vinegar), carbonated drinks (carbonic acid), jams and fruit juices (citric acid), pickles (vinegar), and condiments. It is also used as a preservative in medicines and cosmetics (Cosmetics Database, 2013 and Sodium Benzoate in Robitussin Cough, 2013).Concentration as a food preservative is limited by the FDA in the U.S. to $0.1 \%$ by weight, while it is also allowed as an animal food additive at up to $0.1 \%$, according to AFCO's official publication (Kuheli et al., 2011). Sodium benzoate is also used in the pharmaceutical industry as a treatment for urea cycle disorders due to its ability to bind amino acids, leading to excretion of these amino acids and a decrease in ammonia levels (Wilcken, 2004; Häberle et al., 2012). Baldwin et al. (1995) reported that sodium benzoate is used in the medical and pharmaceutical sectors as antimicrobial agents in edible coatings and antifungal, cosmetics, dental care and clinical pharmaceutical products. It is worthy of note that the effectiveness of sodium benzoate as a preservative increases with decreasing $\mathrm{pH}$ (increasing acidity) (Batshaw and Monahen, 1987). They equally observed that sodium benzoate can be used in the treatment of patients with urea cycle enymopathies (i.e hyperammonemia due to inborn errors of urea synthesis). Other uses of sodium benzoate are available. According to Scholz and Kontmann, (1991) and Srour, (1998), the largest use of sodium benzoate is about 30$35 \%$ of the total demand, which is about 15,000 tonnes of benzoic acid production used as anticorrosive additive to automatic engine anti-freeze coolants and in other waterborne systems. Sodium benzoate is an ester used in the modification of alkyd resin. Most currently, Goodrich Kalama Inc., (1999) stated that sodium benzoate is a new formulation in the production of plastics such as polypropylene, to improve strength and clarity, while BUA, (1995) reported that it can be used as a stabilizer in photographic baths/processing. Sodium benzoate is also used in fireworks as a fuel in whistle mix, a powder that emits a whistling noise when compressed into a tube and ignited. In present investigation, the process performances of the Batch Reactor, Continuous Stirred-Tank Reactor (CSTR) and Plug Flow Reactor (PFR) for the production of sodium benzoate from the reaction of sodium hydroxide and benzoic acid were investigated. The performance equations for the operation of Batch reactor, CSTR and PFR were developed for the analysis of the reactor's functional dimensions and parameters.

\section{MATERIAL AND METHODS}

The model equations for batch, continuous stirred tank and plug flow reactors, as well as the equations relating their functional dimensions and parameters are developed. The resulting respective reactor equations were used for the simulation of the functional parameters, implemented with MATLAB simulink.

\section{Expression of the Rate Kinetics}

The rate equation for the production of sodium benzoate via the reaction of sodium hydroxide and benzoic acid was obtained from the reaction mechanism presented in equation (1) and (2). Thus, from equation (2), the reaction mechanism of the process is expressed thus:

$\mathrm{NaOH}+\mathrm{C}_{6} \mathrm{H}_{5} \mathrm{COOH} \stackrel{k}{\longrightarrow} \mathrm{C}_{6} \mathrm{H}_{5} \mathrm{COONa}+\mathrm{H}_{2} \mathrm{O}$

Or for simplicity, equation (2.1) can be re-written as

$A+B \stackrel{k}{\longrightarrow} C+D$

Where, $A=\mathrm{NaOH}, B=\mathrm{C}_{6} \mathrm{H}_{5} \mathrm{COOH}, \mathrm{C}=\mathrm{C}_{6} \mathrm{H}_{5} \mathrm{COONa}$ and $\mathrm{D}=\mathrm{H}_{2} \mathrm{O}$

The rate equation with respect to sodium hydroxide is expressed as

$-r_{A}=-\frac{d C_{A}}{d t}=k C_{A} C_{B}$

Expressing equation (3) in terms of sodium hydroxide conversion and following the relationship between instantaneous concentration and the initial concentration of reactants expressed by Levenspiel (2004), we obtained as follows.

$C_{A}=C_{A o}-C_{A o} X_{A}$

$C_{A}=C_{A o}\left(1-X_{A}\right)$

$C_{B}=C_{B o}-C_{A o} X_{A}$

$C_{B}=C_{A o}\left(\alpha-X_{A}\right)$

Where, $\alpha$ is the ratio of the initial concentration of benzoic acid to that of sodium hydroxide in the reaction,

$\left(\alpha=\frac{C_{B o}}{C_{A o}}\right)$.

Substitution of equations (4) and (5) into (3) yields

$-r_{A}=k C_{A o}^{2}\left(1-X_{A}\right)\left(\alpha-X_{A}\right)$

But for temperature dependent rate, the specific rate is expressed according to Arrhenius equation given as

$k=k_{o} \exp \left(-\frac{E a}{R T}\right)$

Thus equation (6) becomes

$-r_{A}=k_{o} \exp \left(-\frac{E a}{R T}\right) C_{A o}^{2}\left(1-X_{A}\right)\left(\alpha-X_{A}\right)$ 


\section{Development of reactor performance equations}

The performance equations for batch, continuous stirred-tank and plug flow reactors are developed in this section by applying the principle of conservation of mass and energy as presented in equations (9) and (24), respectively.

\section{Mass balance on batch reactor}

A schematic diagram of batch reactor is presented in Figure 1, where the raw materials are charged into the reactor at once and allowed to react until reaction is completed before withdrawing the product. However, the performance equation is developed as shown in equation (9).

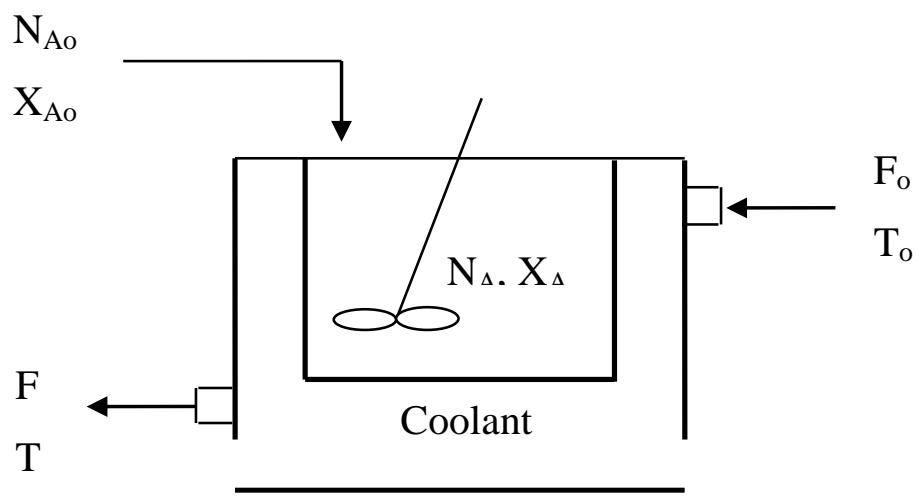

Fig. 1: Batch reactor

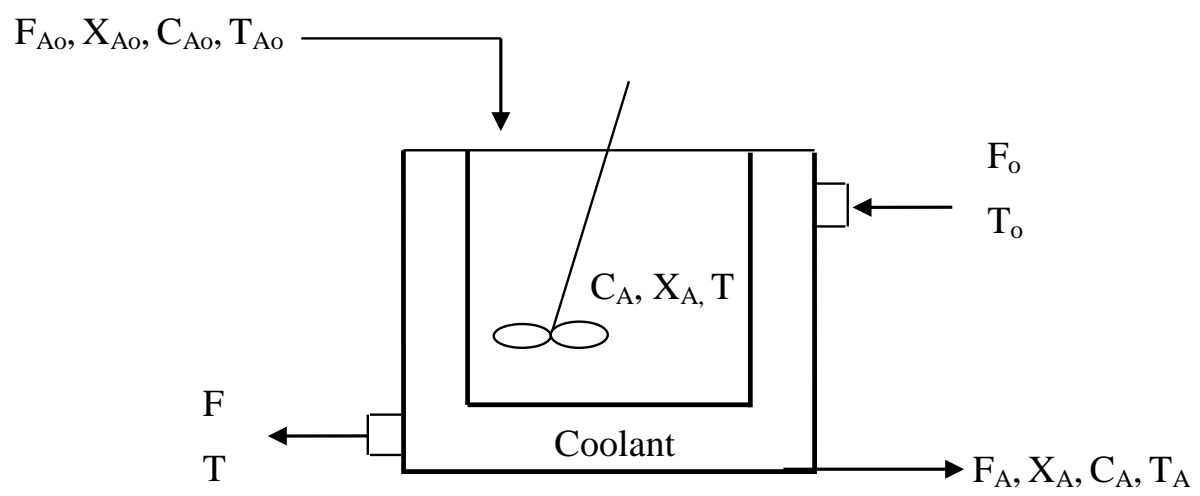

Figure 2: Continuous stirred tank reactor

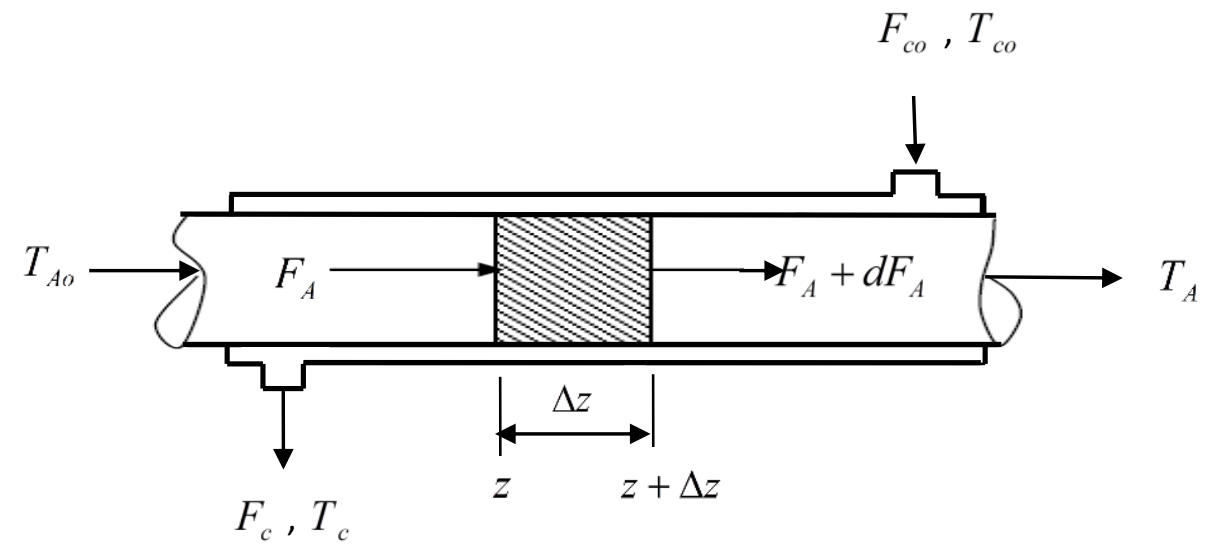

Figure 3: Differential element of plug flow reactor 
$\left\{\begin{array}{c}\text { Rate of } \\ \text { input of } \\ \text { material } \\ \text { into reactor }\end{array}\right\}=\left\{\begin{array}{c}\text { Rate of } \\ \text { output of } \\ \text { material from } \\ \text { reactor }\end{array}\right\}+\left\{\begin{array}{c}\text { Rate of } \\ \text { depletion } \\ \text { due to } \\ \text { reaction }\end{array}\right\}+\left\{\begin{array}{c}\text { Rate of } \\ \text { accumulation } \\ \text { of material } \\ \text { within reactor }\end{array}\right\}$

Input of material $=N_{A o}$

Output of material $=N_{A}$

Rate of depletion $=-r_{A} V_{\text {Batch }}$

Rate of accumulation $=\frac{d N_{A}}{d t}$

Substituting equations (10) through equation (13) into equation (9) yields:

$N_{\text {Ao }}=N_{A}+\left(-r_{A}\right) V_{\text {Batch }}+\frac{d N_{A}}{d t}$

But for batch reactor, $N_{A o}=N_{A}=0$

Hence, $-\frac{d N_{A}}{d t}=\left(-r_{A}\right) V_{\text {Batch }}$

Expressing equation (12) in terms of degree of conversion, we have:

$N_{A}=N_{A o}\left(1-X_{A}\right)$

$\frac{N_{A o}}{V_{\text {Batch }}} \frac{d X_{A}}{d t}=\left(-r_{A}\right)$

Substituting the rate term in equation (8) into (14) gives:

$\frac{N_{A o}}{V_{\text {Batch }}} \frac{d X_{A}}{d t}=C_{A o}^{2}\left(1-X_{A}\right)\left(\alpha-X_{A}\right) k_{o} \exp \left(-\frac{E a}{R T}\right)$

But $C_{A o}=\frac{N_{A o}}{V_{B a t c h}}$

$C_{A o} \frac{d X_{A}}{d t}=C_{A o}^{2}\left(1-X_{A}\right)\left(\alpha-X_{A}\right) k_{o} \exp \left(-\frac{E a}{R T}\right)$

$\frac{d X_{A}}{d t}=C_{A o}\left(1-X_{A}\right)\left(\alpha-X_{A}\right) k_{o} \exp \left(-\frac{E a}{R T}\right)$

\section{Heat generation per unit volume of reactor}

Heat generation per unit volume of reactor is expressed as

$q_{\text {Batch }}=\frac{Q}{V_{\text {Batch }}}$

Where: $Q=\left(-\Delta H_{r}\right) F_{A o} X_{A}$

But for batch reactor, there is no flow of materials thus,

$Q=\left(-\Delta H_{r}\right) \frac{N_{A o}}{t} X_{A}$

Substituting equation (20) into (18) gives

$q_{\text {Batch }}=\frac{\left(-\Delta H_{r}\right) N_{A o} X_{A}}{t V_{\text {Batch }}}$ 


\section{Energy balance on batch reactor}

The energy balance on batch reactor can be expressed as follows using equation (22), we have

$$
\left\{\begin{array}{c}
\text { Rate of } \\
\text { energy } \\
\text { input } \\
\text { into } \\
\text { reactor }
\end{array}\right\}=\left\{\begin{array}{c}
\text { Rate of } \\
\text { energy } \\
\text { output }
\end{array}\right\}+\left\{\begin{array}{c}
\text { Heat } \\
\text { productio } \\
\text { n rate due } \\
\text { to } \\
\text { reaction }
\end{array}\right\}+\left\{\begin{array}{c}
\text { Heat } \\
\text { removal } \\
\text { rate by } \\
\text { coolant }
\end{array}\right\}+\left\{\begin{array}{l}
\text { Accumulat } \\
\text { ion of } \\
\text { energy } \\
\text { within } \\
\text { reactor }
\end{array}\right\}
$$

Energy input $=F_{A o} C_{P o} T_{A o}$

Energy output rate $=F_{A} C_{P} T_{A}$

Heat production rate $=\left(-\Delta H_{r}\right)\left(-r_{A}\right) V_{\text {Batch }}$

Rate of heat removal by coolant $=Q_{\text {rev }}$

Accumulation of energy $=\frac{d H_{A}}{d t}$

Inserting equations (23) through (27) into the energy equation (22) yields

$F_{A o} C_{P o} T_{A o}=F_{A} C_{P} T_{A}+\left(-\Delta H_{r}\right)\left(-r_{A}\right) V_{\text {Batch }}-Q_{r e v}+\frac{d H_{A}}{d t}$

For batch reactor, there is no inflow and outflow of energy, therefore, equation (28) reduces to

$\left(-\Delta H_{r}\right)\left(-r_{A}\right) V_{\text {Batch }}-Q_{r e v}=\frac{d H_{A}}{d t}$

But $H_{A}=N_{A} C_{P} T$ while $Q_{r e v}=U A\left(T_{A}-T_{o}\right)=\frac{\pi D^{2} U}{4}\left(T_{A}-T_{o}\right)$

Where, $A=\frac{\pi D^{2}}{4}=$ Cross sectional area of the batch reactor. Upon substitution, equation (29) into becomes:

$\frac{d T_{A}}{d t}=\frac{\left(-\Delta H_{r}\right)\left(-r_{A}\right) V_{B a t c h}}{N_{A o} C_{P}}+\frac{\pi D^{2} U}{4 N_{A o} C_{P}}\left(T_{A}-T_{o}\right)$

Again, $\frac{N_{A o}}{V_{\text {Batch }}}=C_{A o}$ thus, $\frac{V_{B a t c h}}{N_{A o}}=\frac{1}{C_{A o}}$

Therefore, $\frac{d T_{A}}{d t}=\frac{\left(-\Delta H_{r}\right)\left(-r_{A}\right)}{C_{A o} C_{P}}+\frac{\pi D^{2} U}{4 N_{A o} C_{P}}\left(T_{A}-T_{o}\right)$

Inserting the value of the rate of reaction $\left(-r_{A}\right)$ in equation (8) into equation (31) we have:

$\frac{d T_{A}}{d t}=\frac{\left(-\Delta H_{r}\right) k_{o} \exp \left(-\frac{E a}{R T}\right) C_{A o}^{2}\left(1-X_{A}\right)\left(\alpha-X_{A}\right)}{C_{A o} C_{P}}+\frac{\pi D^{2} U}{4 N_{A o} C_{P}}\left(T_{A}-T_{o}\right)$
$\frac{d T_{A}}{d t}=\frac{\left(-\Delta H_{r}\right) k_{o} \exp \left(-\frac{E a}{R T}\right) C_{A o}\left(1-X_{A}\right)\left(\alpha-X_{A}\right)}{C_{P}}+\frac{\pi D^{2} U}{4 N_{A o} C_{P}}\left(T_{A}-T_{o}\right)$

Equations (17) and (32) are system of ordinary differential equations which must be solved simultaneously since conversion and temperature of the batch reactor are depending on time of the reaction. 


\section{Mass balance on continuous stirred tank reactor (CSTR)}

The development of performance equation of CSTR due to inflow of mass of component into the CSTR and outflow of mass of component from the CSTR was obtained by the application of equation (9), we have

From equation (9), we have that

Input of material $=F_{A 0}$

Output of material $=F_{A}$

Rate of depletion $=-r_{A} V_{C S T R}$

Rate of accumulation $=\frac{d N_{A}}{d t}$

Substituting equation (33) through equation (36) into equation (9) yields

$F_{A 0}=F_{A}+\left(-r_{A}\right) V_{C S T R}+\frac{d N_{A}}{d t}$

The accumulation term for CSTR, $\frac{d N_{A}}{d t}=0$

So that $F_{A 0}-F_{A}=\left(-r_{A}\right) V_{C S T R}$

But $F_{A}=F_{A 0}\left(1-X_{A}\right)$

Substituting equation (39) into equation (38) gives

$F_{A o} X_{A}=\left(-r_{A}\right) V_{C S T R}$

\section{CSTR volume}

From equation (40), the volume of CSTR was obtained as

$V_{C S T R}=\frac{F_{A 0} X_{A}}{\left(-r_{A}\right)}$

Substitution of equation (8) into (41) gives

$V_{C S T R}=\frac{F_{A 0} X_{A}}{k_{o} \exp \left(-\frac{E a}{R T}\right) C_{A o}^{2}\left(1-X_{A}\right)\left(\alpha-X_{A}\right)}$

\section{Height of CSTR}

The height of a cylindrical shape CSTR is given as, $H_{C S T R}=\frac{V_{C S T R}}{\pi R^{2}}$, Hence upon substitution of equation (42) yields

$$
H_{C S T R}=\frac{F_{A 0} X_{A}}{\pi R^{2} k_{o} \exp \left(-\frac{E a}{R T}\right) C_{A o}^{2}\left(1-X_{A}\right)\left(\alpha-X_{A}\right)}
$$

\section{CSTR space time}

This is given mathematically as $S_{\text {TCSTR }}=\frac{V_{C S T R}}{v_{0}}$

Substituting equation (42) into equation (45) yields

$$
S_{\text {TCSTR }}=\frac{F_{A 0} X_{A}}{v_{0} k_{o} \exp \left(-\frac{E a}{R T}\right) C_{A o}^{2}\left(1-X_{A}\right)\left(\alpha-X_{A}\right)}
$$




\section{Space velocity}

This is defined as the number of reactor volume of feed that can be treated in a unit time at specified condition and it is expressed as

$S_{v C S T R}=\frac{v_{0}}{V_{C S T R}}$

Substituting equation (42) into equation (47) yields, $S_{v C S T R}=\frac{v_{o} k_{o} \exp \left(-\frac{E a}{R T}\right) C_{A o}^{2}\left(1-X_{A}\right)\left(\alpha-X_{A}\right)}{F_{A o} X_{A}}$

\section{Heat generated per unit volume of CSTR}

The heat generated per unit volume of CSTR is expressed as

$q_{\text {CSTR }}=\frac{Q}{V_{C S T R}}$

But the total heat generated in the CSTR can be expressed as, $Q=\left(-\Delta H_{r}\right) F_{A 0} X_{A}$

Hence upon substitution of equations (42) and (50) into (49) yields

$q_{C S T R}=\left(-\Delta H_{r}\right) k_{o} \exp \left(-\frac{E a}{R T}\right) C_{A o}^{2}\left(1-X_{A}\right)\left(\alpha-X_{A}\right)$

\section{Energy balance on CSTR}

The energy balance equation on CSTR was obtained by applying equation (22) on Figure 2.

Hence, we that:

Energy input $=F_{A o} C_{P o} T_{A o}$

Energy output rate $=F_{A} C_{P} T_{A}$

Heat production rate $=\left(-\Delta H_{r}\right)\left(-r_{A}\right) V_{C S T R}$

Removed heat by coolant $=Q_{\text {rev }}$

Accumulation of energy $=\frac{d H}{d t}$

Inserting equations (52) through (56) into the energy equation (22) yields

$F_{A o} C_{P o} T_{A o}=F_{A} C_{P} T_{A}-\left(-\Delta H_{r}\right)\left(-r_{A}\right) V_{C S T R}-Q_{r e v}+\frac{d H}{d t}$

For CSTR operating at steady state, accumulation term is equal to zero. Therefore, for constant molar flow rate and heat capacity, equation (57) yields to equation (58) after arrangement.

$V_{C S T R}=\frac{F_{A o} C_{P}\left(T_{A}-T_{A o}\right)+Q_{r e v}}{\left(-\Delta H_{r}\right) k_{o} \exp \left(-\frac{E a}{R T}\right) C_{A o}^{2}\left(1-X_{A}\right)\left(\alpha-X_{A}\right)}$

Substituting the heat removed term in equation (58) gives:

$V_{C S T R}=\left\{\frac{F_{A o} C_{P}\left(T_{A}-T_{A o}\right)+\frac{\pi D^{2} U\left(T_{A}-T_{o}\right)}{4}}{\left(-\Delta H_{r}\right) k_{o} \exp \left(-\frac{E a}{R T}\right) C_{A o}^{2}\left(1-X_{A}\right)\left(\alpha-X_{A}\right)}\right\}$

Again, equations (42) and (59) are system of non-linear equations, which must be solved simultaneously as the volume of the CSTR if a function of conversion and temperature of the process. After obtaining the solution, the CSTR functional parameters were then evaluated using MATLAB. 


\section{Mass balance on plug flow reactor (PFR)}

The development of performance equation of PFR due to inflow of mass of component into the PFR was obtained by the application of equation (9) on the differential element of the hypothetical plug flow reactor shown in Figure 3.

From equation (9), we have that

Input of material $=F_{A}$

Output of material $=F_{A}+d F_{A}$

Rate of depletion $=-r_{A} d V_{\text {plug }}$

Rate of accumulation $=\frac{d N_{A}}{d t}$

Substituting equation (60) through equation (63) into equation (9) yields

$F_{A}=F_{A}+d F_{A}+\left(-r_{A}\right) d V_{p l u g}+\frac{d N_{A}}{d t}$

But the accumulation term for PFR is zero (i.e $\frac{d N_{A}}{d t}=0$ ); thus equation (64) after simplification becomes

$-d F_{A}=\left(-r_{A}\right) d V_{p l u g}$

In terms of sodium hydroxide conversion, $X_{A}$ and noting that, $F_{A}=F_{A o}\left(1-X_{A}\right)$

Hence, equation (3.65) can be further expressed as

$-d\left[F_{A o}\left(1-X_{A}\right)\right]=\left(-r_{A}\right) d V_{p l u g}, d X_{A}=\left(-r_{A}\right) d V_{p l u g}$

\section{PFR volume}

From equation (66), the volume of PFR was obtained as, $d V_{p l u g}=\frac{F_{A o} d X_{A}}{\left(-r_{A}\right)}$

Substitution of the rate expression in equation (8) into (67) gives

$\frac{d X_{A}}{d V_{p l u g}}=\frac{k_{o} \exp \left(-\frac{E a}{R T}\right) C_{A o}^{2}\left(1-X_{A}\right)\left(\alpha-X_{A}\right)}{F_{A o} d X_{A}}$

\section{Length of PFR}

For a cylindrical shape reactor, the length of PFR is given by, $L_{p l u g}=\frac{V_{p l u g}}{\pi R^{2}}$

\section{Space time of PFR}

The space time of plug flow reactor is expressed as, $S_{\text {Tplug }}=\frac{V_{p l u g}}{v_{o}}$

\section{Space velocity of PFR}

The space velocity of plug flow reactor is expressed as, $S_{v p l u g}=\frac{v_{o}}{V_{p l u g}}$ 


\section{Heat Generation per unit PFR volume}

Heat generation per unit volume of reactor is expressed as

$q_{\text {plug }}=\frac{Q}{V_{\text {plug }}}$

But $Q=\left(-\Delta H_{r}\right) F_{A o} X_{A}$

Substitution of equation (73) into (72) gives, $q_{\text {plug }}=\frac{\left(-\Delta H_{r}\right) F_{A o} X_{A}}{V_{p l u g}}$

\section{Pressure drop along PFR}

Pressure drop is one of the major characteristics of plug flow reactor hence and Simmie, (2003) has expressed the pressure drop in a tubular flow system as

$\Delta P=\frac{8 f L \rho u^{2}}{2 D}=\frac{4 f L \rho u^{2}}{D}$

Where: $f=\frac{0.04}{(\operatorname{Re})^{0.16}}$, But $\operatorname{Re}=\frac{\rho u D}{\mu}$, Hence $f=\frac{0.04 \mu^{0.16}}{(\rho u D)^{0.16}}$

Combining equation (75) and (76) with further simplification gives, $\Delta P=\frac{0.16 L \rho^{0.84} u^{1.84} \mu^{0.16}}{D^{1.16}}$

\section{Energy balance equation}

The energy balance equation on plug flow reactor was obtained by applying equation (22) on Figure 3. Hence from equation (22), we have that

Rate of input of energy $=F_{A} C_{P} T_{A}$, Rate of output of energy $=F_{A} C_{P} T_{A}+d\left(F_{A} C_{p} T_{A}\right)$

Rate of heat of reaction $=\left(-\Delta H_{r}\right)\left(-r_{A}\right) d V_{\text {plug }}$, Rate of heat removal $=Q_{\text {rev }}=U A \Delta T d V_{\text {plug }}$

Rate of accumulation of energy $=\frac{d H}{d t}$, Substituting the above equations into equation (22) gives

$F_{A} C_{p} T_{A}=F_{A} C_{p} T_{A}+d\left(F_{A} C_{p} T_{A}\right)-\left(-\Delta H_{r}\right)\left(-r_{A}\right) d V_{p l u g}-U A \Delta T d V_{p l u g}+\frac{d H}{d t}$

For steady state reactor operation, constant heat capacity and molar flow rate, equation (78) becomes

$F_{A} C_{p} d T_{A}=\left(-\Delta H_{r}\right)\left(-r_{A}\right) d V_{p l u g}+U A \Delta T d V_{p l u g}$

Dividing all through by $F_{A} C_{p} d V_{p l u g}$

$\frac{d T}{d V_{\text {plug }}}=\frac{\left(-\Delta H_{r}\right)\left(-r_{A}\right)+U A \Delta T}{F_{A} C_{p}}$

But $A=\frac{\pi D^{2}}{4}, \Delta T=\left(T_{A}-T_{o}\right)$ and $F_{A}=F_{A o}\left(1-X_{A}\right)$

Upon substitution into equation (80) and replacing the reaction terms in equation (8) we have:

$\frac{d T}{d V_{\text {plug }}}=\left\{\frac{\left(-\Delta H_{r}\right) k_{o} \exp \left(-\frac{E a}{R T}\right) C_{A o}^{2}\left(1-X_{A}\right)\left(\alpha-X_{A}\right)+\frac{\pi D^{2} U\left(T_{A}-T_{o}\right)}{4}}{F_{A o}\left(1-X_{A}\right) C_{p}}\right\}$ 


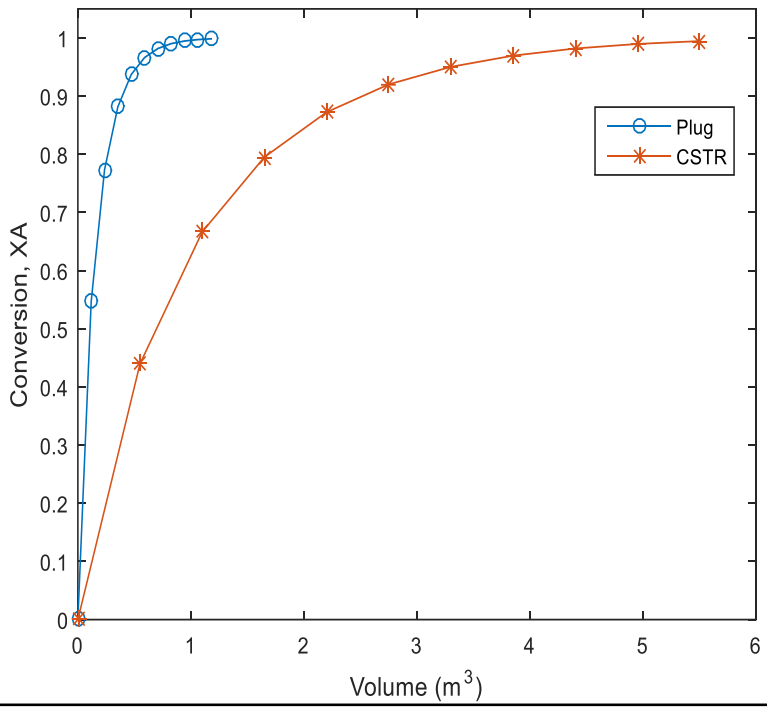

Fig. 4: Size comparison of reactors at increasing conversion

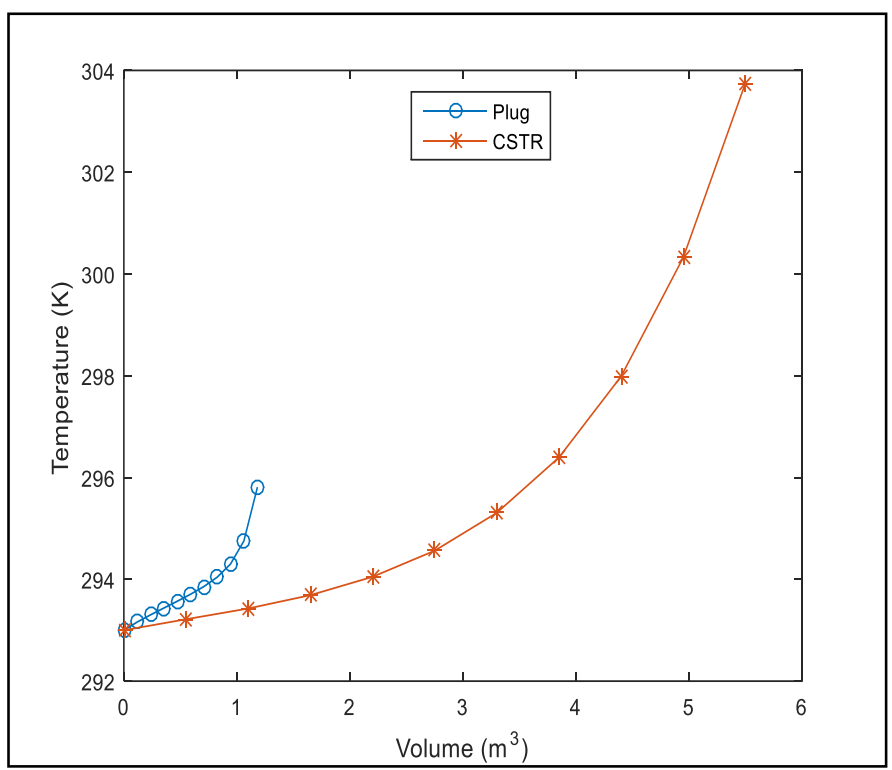

Fig. 5: Size comparison of reactors at increasing temperature

Similarly, equations (68) and (82) are system of ordinary differential equations (ODE), which must be solved simultaneously as conversion and temperature are function of the volume of plug flow reactor. The system of the ordinary differential equations was solved numerically using Runge-Kutta algorithm implemented in MATLAB computer program. After solving the ODE's, the PFR functional parameters were then evaluated. The simulation was implemented in MATLAB to facilitate the processing of output data for the batch, continuous stirred-tank and plug flow reactors.

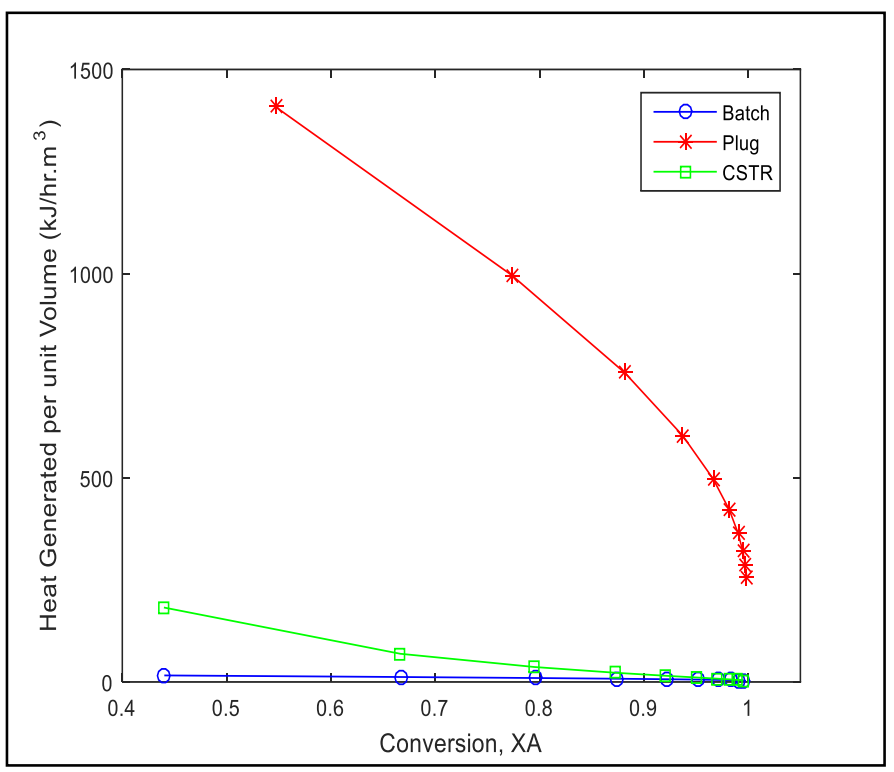

Fig. 6: Comparison of heat generated per unit volume of reactor types at increasing conversion

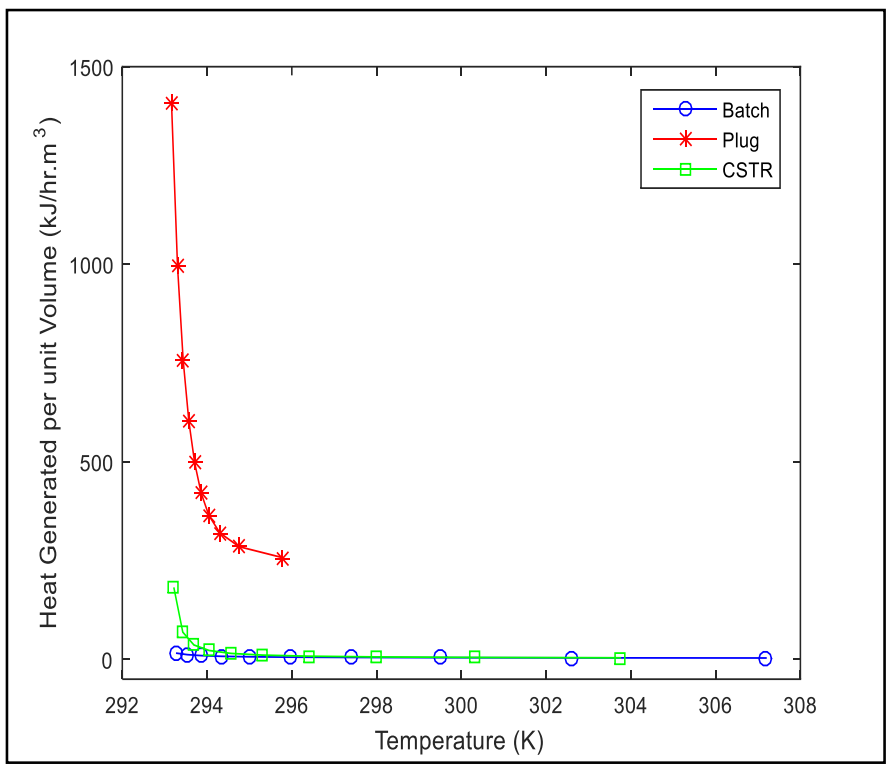

Fig. 7: Comparison of heat generated per unit volume of reactor types at increasing temperature

\section{Simulation parameters}

The inputs parameters used to perform the calculation and evaluation of the reactor functional parameters and dimensions are presented in Table 1.

\section{RESULTS AND DISCUSSION}

The performances of batch reactor, plug flow reactor and continuous stirred-tank reactor at various molar feed 


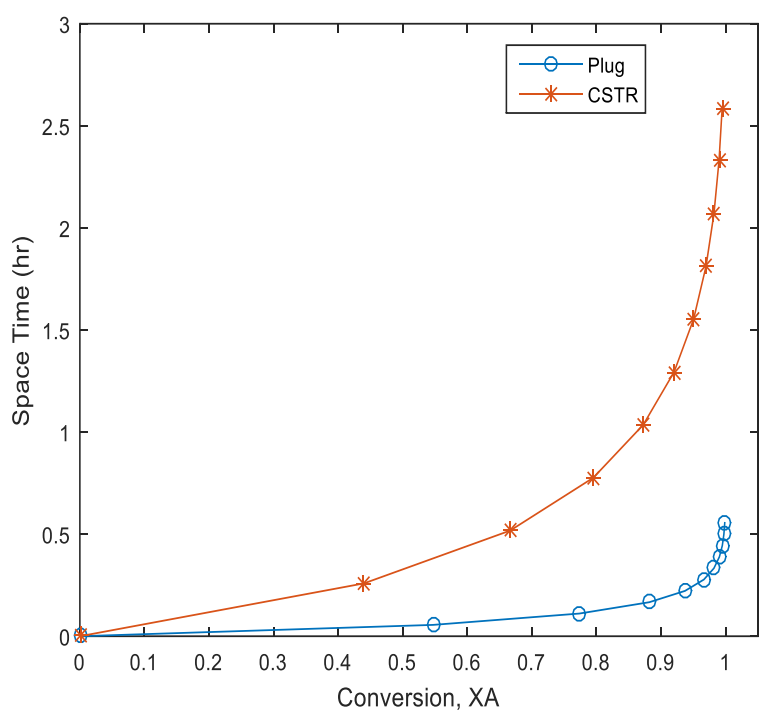

Fig. 8: Comparison of space time of CSTR and PFR at increasing conversion

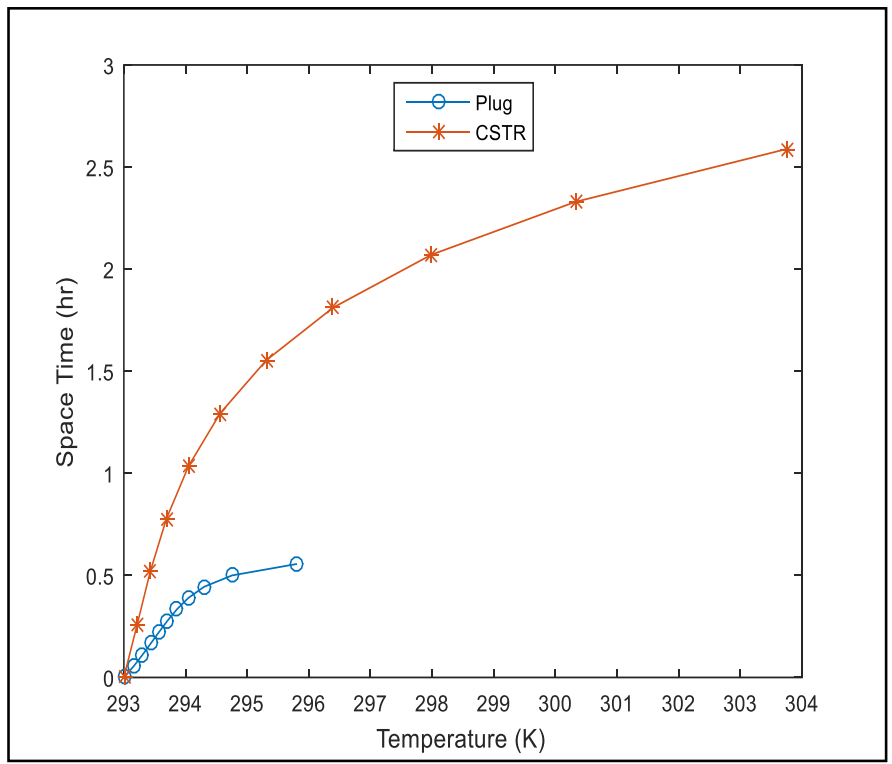

Fig. 9: Comparison of space time of CSTR and PFR at increasing temperature

ratios, for the production of sodium benzoate have been investigated and presented.

The heat generated per reactor volume for the three reactors was analysed and also compared. As continuous reactors, the plug flow reactor and the continuous stirred-tank reactor functional parameters such as size, space time and space velocity were analysed and compared. Furthermore, the pressure drop as one of the major characteristics associated with plug flow reactor was evaluated against the increase in degree of conversion of

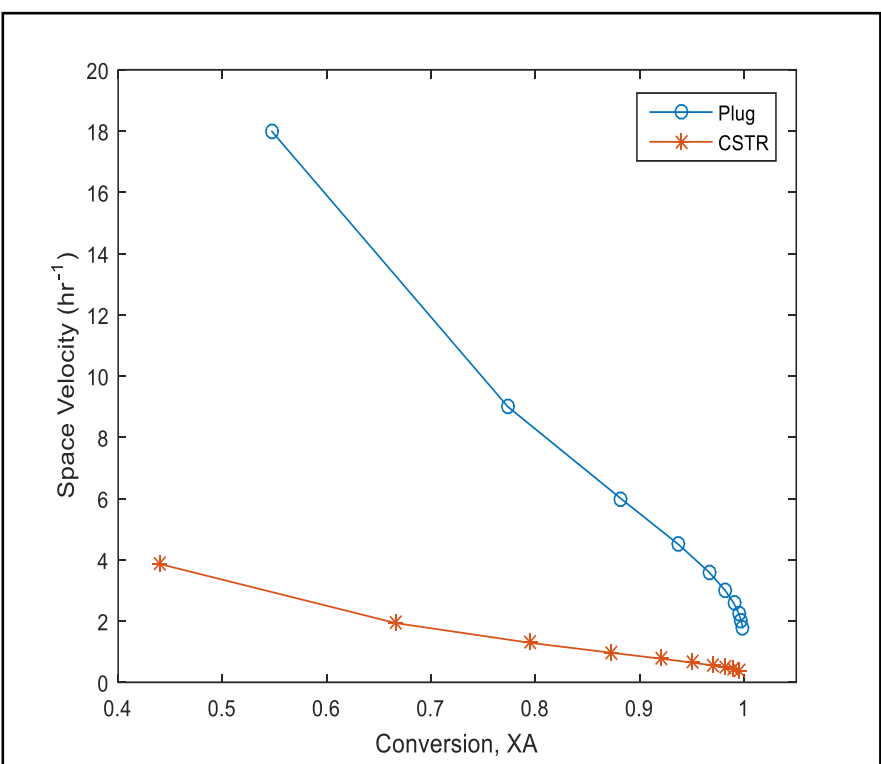

Fig. 10: Comparison of space velocity of CSTR and PFR at increasing conversion

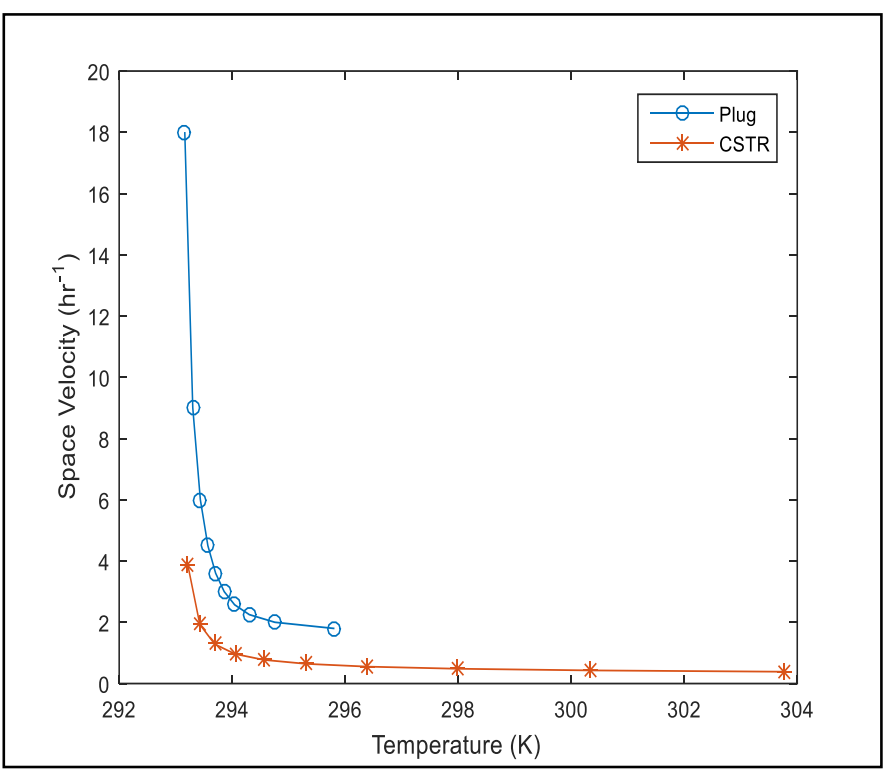

Fig. 11: Comparison of space velocity of CSTR and PFR at increasing temperature

sodium hydroxide and operating temperature at varied molar feed ratios.

\section{Comparison of the reactors functional parameters}

The heat generation per reactor volume for batch, continuous stirred-tank and plug flow reactors were compared with respect to conversion and temperature as shown in Figures 4 and 5, while the reactor volume were only compared for CSTR and PFR since the evaluation was done at constant batch volume. Also, the performance 
Table 1: Summary of input parameters

\begin{tabular}{lcc}
\hline Parameter & Value & References \\
\hline Initial concentration, $C_{A o}\left(\mathrm{~mol} / \mathrm{m}^{3}\right)$ & 23.9 & Kralj $(2012)$ \\
Volumetric flow rate $\left(\mathrm{m}^{3} / \mathrm{h}\right)$ & 2.125 & Assumed \\
Heat of reaction, $\Delta H_{r}(\mathrm{~kJ} / \mathrm{mol})$ & 303.92 & Kralj $(2012)$ \\
Coefficient of Heat transfer, $U\left(\mathrm{~kJ} / \mathrm{m}^{2} . \mathrm{K}\right)$ & 140 & Assumed \\
Mean specific heat capacity, $C_{p}(\mathrm{~kJ} / \mathrm{mol} . \mathrm{K})$ & 150 & Assumed \\
Density, $\left(\mathrm{kg} / \mathrm{m}^{3}\right)$ & 1530 & Linstrom and Mallard (2014) \\
Mean viscosity, $\mu\left(\mathrm{Ns} / \mathrm{m}^{2}\right)$ & $1.8722 \times 10^{-5}$ & Linstrom and Mallard $(2014)$ \\
Molar flow rate, $F_{A o}(\mathrm{kmol} / \mathrm{h})$ & 40.0 & Assumed \\
Activation energy, $E a(\mathrm{~kJ} / \mathrm{kmol})$ & 35082.59 & Kralj $(2012)$ \\
Pre-exponential factor, $k_{o}\left(\mathrm{~m}^{3} / \mathrm{kmol} . \mathrm{h}\right)$ & 788588.57 & Kralj $(2012)$ \\
\hline
\end{tabular}

Table 2: Performance of batch reactor, CSTR and PFR parameters at same operational conditions

\begin{tabular}{llll}
\hline Parameters & Batch Reactor & CSTR & PFR \\
\hline Temperature (K) & 307.2 & 304.8 & 295.8 \\
Time of Reaction (h) & 2.0 & N/A & N/A \\
Conversion (\%) & 99.57 & 99.46 & 99.86 \\
Diameter (m) & 2.20 & 2.20 & 0.30 \\
Volume (m ${ }^{3}$ ) & 6.5 & 5.50 & 1.18 \\
Height $/$ Length (m) & 1.71 & 1.45 & 16.69 \\
Space Time (h) & N.A & 2.59 & 0.56 \\
Space Velocity (h-1) & N.A & 0.39 & 1.80 \\
Heat Generated per Reactor Volume $\left(\mathrm{kJ} / \mathrm{h}^{-1} \mathrm{~m}^{3}\right)$ & 3.62 & 4.12 & 257.19 \\
Pressure Drop $\left(\mathrm{N} / \mathrm{m}^{2}\right)$ & N.A & N.A & 4.06 \\
\hline
\end{tabular}

measures for continuous flow reactors: space time and space velocity were compared for continuous stirred-tank and plug flow reactors.

The degree of conversion of sodium hydroxide for the CSTR and PFR investigated in this research was compared with the respective reactor types at molar feed ratio of 3.0. Generally as shown in Figure 4, the degree of conversion of sodium hydroxide increases with increase in volume of the respective reactor. However, at the same reactors' conditions, the size of continuous stirred-tank reactor required for the synthesis of sodium benzoate from sodium hydroxide and benzoic acid was far greater than that plug flow reactor. Despite having a smaller volume, the degree of conversion at the same operating conditions was higher in PFR than in CSTR. Thus, at maximum volumes of CSTR and PFR of $5.5 \mathrm{~m}^{3}$ and $1.18 \mathrm{~m}^{3}$, the the degree of conversion were $99.4 \%$ and $99.86 \%$, respectively.

Similarly, the operating temperature for the CSTR and PFR was compared with the respective reactor types at molar feed ratio of 3.0. Again, as shown in Figure 5, the reactor operating temperature increases non-linearly with increase in volume of the respective reactor. Thus, as with conversion at the same reactors' conditions, the size of continuous stirred-tank reactor required for the synthesis of sodium benzoate from sodium hydroxide and benzoic acid was greater than that plug flow reactor. The conversion of the reactants to the desired product was attained at lower temperature in PFR than in CSTR. This result collaborated Forgler's explanation that smaller volume are required for processing of chemical products in PFR than in CSTR (Forgler, 2006). At molar feed ratio of 3.0 and maximum CSTR and PFR volumes of $5.5 \mathrm{~m}^{3}$ and 1.18 $\mathrm{m}^{3}$, the reaction temperatures were $303.8 \mathrm{~K}$ and $295.8 \mathrm{~K}$, respectively.

The heat generated per reactor volume of the three reactors investigated for the production of sodium benzoate from sodium hydroxide and benzoic acid, was compared at molar feed ratio of 3.0. Figure 6 shows the profiles of the heat generated per reactor volume for the reactors, which decreases with increase in the degree of conversion of sodium hydroxide. Interestingly, the heat generated per reactor volume for batch was far less than those of the continuous stirred-tank and plug flow reactors. Nevertheless, the plug flow reactor generated more heat 
per reactor volume than the continuous stirred-tank reactor. This high variation in the heat generation per reactor volume was due to the small size requirement for the plug flow reactor as compared to the other two reactors. The heat generated per reactor volume and degree of conversion obtained at same reactor operational conditions and molar feed ratio of 3.0 were $3.62 \mathrm{~kJ} / \mathrm{h} . \mathrm{m}^{3}$ and $99.57 \% ; 4.12 \mathrm{~kJ} / \mathrm{h} . \mathrm{m}^{3}$ and $99.46 \%$; and $257.19 \mathrm{~kJ} / \mathrm{h} . \mathrm{m}^{3}$ and $99.86 \%$ for batch reactor, continuous stirred-tank reactor and plug flow reactor, respectively.

The heat generated per reactor volume for the three reactors was also compared as operating temperature increases at the same reactor operating conditions and molar feed ratio of 3.0. Again, as shown in Figure 7, the heat generated per reactor volume for the reactors decreases with increase in reactor operating temperature. As the profile indicated in the figure, the heat generated per reactor volume for batch reactor was less than those of continuous stirred-tank and plug flow reactors. Interestingly, the heat generated by plug flow reactor was far more than those of batch and CSTR, but this was at only a small temperature increase compared to the other two. This high variation in the heat generation per reactor volume was due to the small size requirement for the plug flow reactor as compared to the PFR as against the batch reactor and CSTR. The maximum heat generated per reactor volume and reactor operating temperature obtained at same reactor operational conditions and molar feed ratio of 3.0 were $3.62 \mathrm{~kJ} / \mathrm{h} . \mathrm{m}^{3}$ and $307.2 \mathrm{~K} ; 4.12$ $\mathrm{kJ} / \mathrm{h} . \mathrm{m}^{3}$ and $303.8 \mathrm{~K}$ and $257.19 \mathrm{~kJ} / \mathrm{h}^{\mathrm{m}} \mathrm{m}^{3}$ and $295.8 \mathrm{~K}$ for batch reactor, continuous stirred-tank reactor and plug flow reactor respectively. Thus, reaction was completed in the batch reactor at higher temperature, followed by the CSTR and lastly, the PFR.

Figure 8 showed the comparison of space time in CSTR and PFR at molar feed ratio of 3.0 and of course, same reactor operational conditions. From the profiles, there was a remarkable gap between the space time of CSTR and the space time of PFR. Although, the space time of the both reactors increases with increase in degree of conversion, the CSTR space time increases higher than the PFR space time. Hence, one reactor volume of feed at every degree of conversion of sodium hydroxide will be treated in lesser time with PFR than with CSTR. The maximum space time and degree of conversion obtained at same reactor operational conditions and molar feed ratio of 3.0 were $2.59 \mathrm{~h}$ and $99.46 \%$ and $0.56 \mathrm{~h}$ and $99.86 \%$ for the continuous stirred-tank reactor and plug flow reactor, respectively.

Figure 9 showed the comparison of CSTR space time and PFR space time at molar feed ratio of 3.0 with same reactor operational conditions. Again, like the comparison with conversion, there was different in response to temperature between the space time of CSTR and the space time of PFR. The space time of the both reactors increases with increase in reactor operating temperature, but the CSTR space time increases further as reaction in the PFR was completed at earlier temperature compared to the CSTR. Therefore, one reactor volume of feed at temperature will be treated in lesser time with PFR than with CSTR. The maximum space time and operating temperature obtained at same reactor operational conditions and molar feed ratio of 3.0 were $2.59 \mathrm{~h}$ and $303.8 \mathrm{~K}$; and $0.56 \mathrm{~h}$ and $295.8 \mathrm{~K}$ for the continuous stirredtank reactor and plug flow reactor, respectively.

Figure 10 showed the comparison of CSTR space velocity and PFR space velocity at molar feed ratio of 3.0 and same operational parameters. Again, there was a wide gap between the CSTR space velocity and PFR space velocity. Although, the space velocity of the both reactors decreases as conversion increases, the CSTR space velocity unlike the space time was far less than the PFR space velocity. Again, more number of reactor volumes of feed will be treated per hour at every degree of conversion of sodium hydroxide with PFR than in CSTR. The maximum space velocity and degree of conversion of sodium hydroxide obtained at same reactor operational conditions and molar feed ratio of 3.0 were $0.39 \mathrm{hr}^{-1}$ and $99.46 \%$; and $1.80 \mathrm{hr}^{-1}$ and $99.86 \mathrm{~K}$ for the continuous stirred-tank reactor and plug flow reactor respectively.

Figure 11 showed the comparison of CSTR space velocity and PFR space velocity at molar feed ratio of 3.0 and same operational parameters. The effect of temperature was obviously observed between the space velocity of CSTR and that of the PFR. While the reaction in PFR was attained at a little increase in temperature, the CSTR takes a much more increase in temperature before reaction was completed to achieve a very high conversion. Indeed, the space velocity for the both reactors decreases as conversion was increased, but the CSTR space velocity unlike the space time was less than the PFR space velocity. Again, more number of reactor volumes of feed will be treated per hour at every degree of conversion of sodium hydroxide with PFR than with CSTR. The maximum space velocity and operating temperature obtained at same reactor operational conditions and molar feed ratio of 3.0 were $0.39 \mathrm{~h}^{-1}$ and $303.8 \mathrm{~K}$; and $1.80 \mathrm{~h}^{-1}$ and $295.8 \mathrm{~K}$ for the continuous stirred-tank reactor and plug flow reactor respectively. The values of the reactors functional parameters obtained from the analysis at the same reactor operating parameters and molar feed ratio of 3.0 are summarized in Table 2. Results revealed that the method adopted is efficient for the comparison of sodium benzoate production (Cui et al., 2013; Kiel et al., 2014; Lindsay et al., 2008; Manan et al., 2016; Shi et al., 2014ab; Sirisansaneeyakul et al., 2014; Suryawanshi et al., 2018; Yang et al., 2019; Yang and Lin, 2011) and can also be extended for other products in the industry.

\section{CONCLUSIONS}

Performance equations for batch reactor, plug flow reactor (PFR) and continuous stirred tank reactor (CSTR) have been modeled for the production of sodium benzoate from the 
reaction of sodium hydroxide and benzoic acid. The performance equations were solved and simulated using MATLAB R2015a, to facilitate the analysis of the reactors parameters. The analysis was performed at different molar feed ratios and at same operational parameters. From the result analysis of the batch reactor, it was observed that at 2 hours, conversion, temperature and heat generated per reactor volume increases as molar feed ratio was increased. For CSTR and PFR, degree of conversion and operating temperature increases as size and space time of the reactors were increased. The molar feed ratio as influenced the reactor parameters performance, as increase in molar feed ratio causes improvement in the conversion of sodium hydroxide. Especially, at molar feed ratio of 3.0, the conversion in all the reactors was a few fractions above $99 \%$. On the basis of comparison at the same operating conditions, the overall size of batch reactor was greater than that of CSTR which in turn was greater than that of the PFR, while the reverse was the case for heat generated per reactor volume. Also, the space time for CSTR was greater than that of the PFR while, the space velocity for PFR was greater than that of CSTR. Because the batch reactor and CSTR are not often characterized by pressure drop, no comparison was made. However, the pressure drop along the length of the PFR increases as molar feed ratio was increased. Following the results obtained from the analysis, the production of sodium benzoate from sodium hydroxide and benzoic acid can be executed in either of batch reactor, CSTR or PFR depending on the capacity of production and conditions of operation.

\section{REFERENCES}

Baldwin, E. A., Nisperos_Carriedo, M.O., Baker, R.A., 1995. Use of edible coatings to preserve quality of lightly (and slightly) processed products, Critical Reviews in Food Science and Nutrition 35(6), 509-524.

Batshaw, M.L., Monahan, P.S., 1987. Treatment of urea cycle disorders, Enzyme, 38, 242-250.

BUA. 1995. BUA-Stoffbericht Benzoesaeure Natriumbenzoat Beratergremium fur Umweltrelevante Alstoffe, Stuttgart, Hirzel Verlag (Stoffbericht Nr. 145).

Cosmetics Database. 2013. Skin deep cosmetics database: Environmental working group. Retrieved from http://www.cosmeticsdatabase.com/product.php?prod_i $\mathrm{d}=497795^{\text {th }}$ June, 2017.

Cui, Y., Wang, Y., Fan, K., Dai, W.-L., 2013. Surface structural evolution of $\mathrm{AuAg} / \mathrm{TiO} 2$ catalyst in the transformation of benzyl alcohol to sodium benzoate. Applied Surface Science 279, 391-399.

Fogler, H. S. (2006). Elements of Chemical Reaction Engineering (4th Ed.), New Jersey, USA: Pearson Education Inc.
Goodrich Kalama Incorporation. 1999. Benzoic acid product information bulletin, Kalama, WA.

Häberle, J., Boddaert, N., Burlina, A., Chakrapani, A., Dixon, M., Huemer, M., Karall, D., Martinelli, D., Crespo, P. S., Santer, R., Servais, A., Valayannopoulos, V., Lindner, M., Rubio, V., Dionisi-Vici, C., 2012. Suggested guidelines for the diagnosis and management of urea cycle disorders, Orphanet Journal of Rare Diseases 7(32), 348-354.

Kiel, M., Dobslaw, D., Engesser, K.-H., 2014. Comparison of biological and chemical treatment processes as costeffective methods for elimination of benzoate in saline wastewaters. Water Research 66, 1-11.

Kralj, A.K., 2012. Determining the characteristics of sodium benzoate production using mathematical method, Journal of Applied Solution Chemistry and Modeling 1, 25-37.

Levenspiel, 0., 2004. Chemical Reaction Engineering ( $3^{\text {rd }}$ Edition), Singapore: John Wiley \& Sons.

Lindsay, D., Ntoampe, M., Gray, V.M., 2008. Biodegradation of sodium benzoate by a Gram-negative consortium in a laboratory-scale fluidized bed bioreactor. Bioresource technology 99, 5115-5119.

Linstrom, P.J., Mallard, W.G., 2014. NIST Chemistry WebBook, NIST Standard Reference Database Number 69, National Institute of Standards and Technology, Gaithersburg MD. http://webbook.nist.gov/cgi/cbook.cgi?ID=C65850\&Mas $\mathrm{k}=\mathrm{FFFF} \&$ Units=SI 11 $1^{\text {th }}$ August, 2017.

Manan, F.M.A., Rahman, I.N.A., Marzuki, N.H.C., Mahat, N.A., Huyop, F., Wahab, R.A., 2016. Statistical modelling of eugenol benzoate synthesis using Rhizomucor miehei lipase reinforced nanobioconjugates. Process Biochemistry 51, 249-262.

Scholz, W., Kortmann, W., 1991. Paint Additives In: Elvers, B., Hawkins, S., Schulz, G. (2008). Ulmann's Encyclopedia of Industrial Chemistry, Weinheim, Germany: Verlagsgeselischaft.

Shi, X.-Y., Li, W.-W., Yu, H.-Q., 2014a. Key parameters governing biological hydrogen production from benzoate by Rhodopseudomonas capsulata. Applied energy 133, 121-126.

Shi, X.-Y., Li, W.-W., Yu, H.-Q., 2014b. Optimization of H2 photo-fermentation from benzoate by Rhodopseudomonas palustris using a desirability function approach. International Journal of hydrogen energy 39, 4244-4251.

Simmie, J.M., 2003. Detailed chemical kinetic models for the combustion of hydrocarbon fuels, Progress in Energy and Combustion Scienc 29, 599-634.

Sirisansaneeyakul, S., Kop, B., Tochampa, W., Wannawilai, S., Chaveesuk, R., Lee, W.-C., 2014. Sodium benzoate 
stimulates xylitol production by Candida mogii. Journal of the Taiwan Institute of Chemical Engineers 45, 734743.

Sodium Benzoate in Robitussin Cough. 2013. http://www.rxmed.com/b.main/b2.pharmaceutical/b2. 1.monographs/CPS-\%20Monographs/CPS-

$\% 20$ (General\%20Monographs\%20R)/ROBITUSSIN.html 5th June, 2017.

Srour, R., 1998. Benzoic Acid and Derivatives, Paris, France: (Unpublished Report).

Suryawanshi, P.L., Gumfekar, S.P., Bhanvase, B.A., Sonawane, S.H., Pimplapure, M.S., 2018. A review on microreactors: Reactor fabrication, design, and cutting-edge applications. Chemical Engineering Science 189, 431448.

Wilcken, B., 2004. Problems in the management of urea cycle disorders, Molecular Genetics and Metabolism 81(1), 8691.

Yang, B., Wang, Q., Ye, J., Xu, H., Liu, Y., Li, F., Song, X., Liu, J., Wang, Z., Sand, W., 2019. Performance and microbial protein expression during anaerobic treatment of alkalidecrement wastewater using a strengthened circulation anaerobic reactor. Bioresource technology 273, 40-48.

Yang, H.-M., Lin, D.-W., 2011. Third-liquid phase-transfer catalyzed esterification of sodium benzoate with novel dual-site phase-transfer catalyst under ultrasonic irradiation. Catalysis Communications 14, 101-106.

Visit us at: http://bosaljournals.com/chemint/ Submissions are accepted at: editorci@bosaljournals.com 